\title{
GIS-based prediction of malaria risk in Egypt
}

A.N. Hassan, ${ }^{1}$ M.A. Kenawy, ${ }^{2}$ H. Kamal, ${ }^{3}$ A.A. Abdel Sattar ${ }^{1}$ and M.M. Sowilem ${ }^{4}$

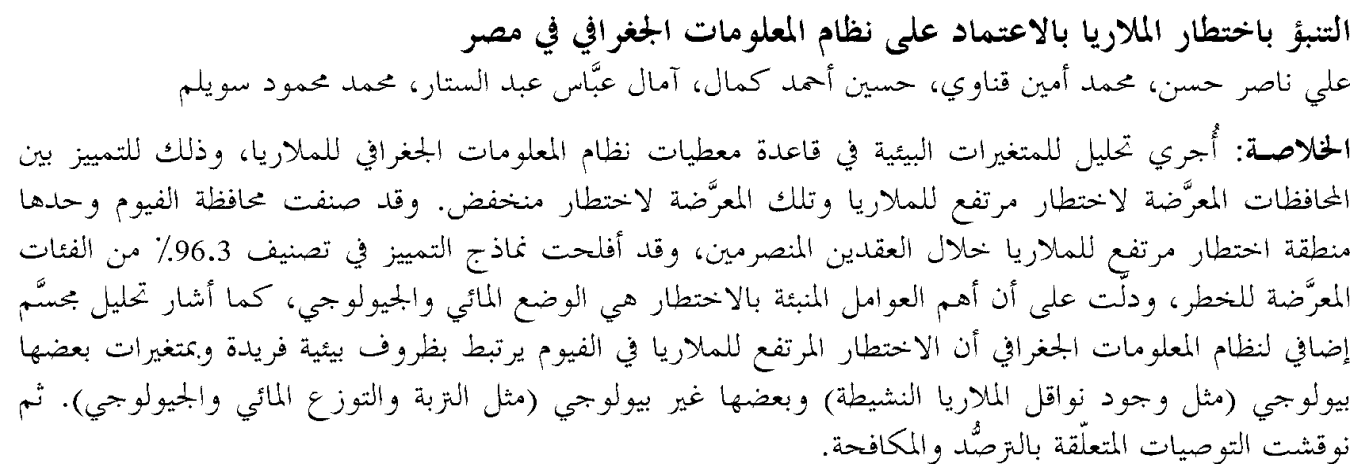

ABSTRACT Environmental variables in a malaria geographic information system (GIS) database were analysed to discriminate between governorates at high and low risk of malaria. Only Fayoum governorate was categorized as a high risk area for malaria during the last 2 decades. Discriminant models correctly classified $96.3 \%$ of the risk categories and indicated that the most important predictor of risk is hydrogeology. Further GIS spatial analysis indicated that the high malaria risk in Fayoum is associated with a unique environmental envelope of biotic (presence of both efficient malaria vectors) and abiotic (hydrogeology and soil) variables. Recommendations for surveillance and control are discussed.

Prévision du risque de paludisme basée sur le SIG en Egypte

RESUME Les variables environnementales dans une base de données du système d'information géographique (SIG) sur le paludisme ont été analysées pour distinguer les gouvernorats à haut risque des gouvernorats à faible risque de paludisme. Seul le gouvernorat de Fayoum a été classé comme zone à haut risque pour le paludisme au cours des 2 dernières décennies. Des modèles discriminants ont correctement classé $96,3 \%$ des catégories de risques et indiqué que le facteur prédictif le plus important était l'hydrogéologie. Une analyse spatiale du SIG a indiqué que le risque élevé de paludisme à Fayoum était associé à une enveloppe environnementale unique de variables biotiques (présence de deux vecteurs du paludisme efficaces) et abiotiques (hydrogéologie et sol). Des recommandations pour la surveillance et la lutte sont examinées.

${ }^{1}$ Institute of Environmental Studies and Research; ${ }^{2}$ Research and Training Centre on Vectors of Disease, Ain Shams University, Cairo, Egypt.

${ }^{3}$ Ministry of Health and Population, Cairo, Egypt.

${ }^{4}$ National Authority for Remote Sensing and Space Sciences, Cairo, Egypt. 


\section{Introduction}

Malaria has been a well-known disease in Egypt since ancient times [1]. It has been endemic in many parts of the country but in recent years Fayoum governorate has represented the only focus. Currently, no malaria is recorded in the country (Ministry of Health and Population, Egypt, unpublished data, 2002). Of the 11 indigenous anopheline mosquitoes, 2 species, Anopheles pharoensis and An. sergentii, are proven vectors in Egypt [1,2].

Although a significant resurgence of the disease is unlikely in Egypt at present, the risk of localized outbreaks of malaria cases due to infection of local anopheline mosquitoes by imported cases does exist. Several factors contribute to this risk including the continual movement of people between Aswan governorate and Sudan and the influx of large populations from Africa and Asia to Cairo and other cities for educational and religious purposes. Rapid environmental change brought about by water resources development projects (e.g. Toshka and El Salam Canal) also contributes to the risk. Linkage between these types of environmental change and risk of vector-borne disease transmission are well documented [3].

In an attempt to assist preparedness planning, surveillance and control of malaria during current rapid socioeconomic and environmental changes, a georeferenced database for malaria management in Egypt was developed jointly by Ain Shams University, Cairo and the Ministry of Health and Population (MOHP). The geographic information system (GIS) database integrates epidemiologic, environmental and socioeconomic data that provide important inputs to the decision-making process in malaria management by MOHP. Our study communicates the results of statistical and spatial analyses carried out to develop upto-date vector distribution maps, identify disease risk predictors and generate risk maps to assist surveillance and control of malaria in Egypt.

\section{Methods}

\section{Geographic information system database}

The database was built in ArcView GIS (ESRI, Redlands, California). An administrative map of Egypt delineating the governorate boundaries $(1: 1000000)$ was digitized and used as the base map to which all thematic data are spatially linked.

\section{Mosquito vector data}

Information on the distribution of Anopheles mosquitoes in all governorates was collected from published data and MOHP mosquito surveillance records. In addition, mosquito larval surveys were carried out in Ismailia, Port Said, North Sinai (El Salam irrigation project), South Sinai, Red Sea and Aswan (Toshka agriculture project) governorates during 2002 and 2003 to update anopheline mosquito distribution. No data on mosquito abundance were used as they were not included in all reviewed articles and when present, different sampling methods had been used.

\section{Malaria parasite prevalence}

Historical data on malaria parasite prevalence covering the period 1971-2001 were provided by the Department of Malaria, Filariasis and Leishmaniasis, MOHP. The data included yearly records of the total number of persons examined and the total number of positive cases per governorate.

المجلة الصحية لشرق المتوسط، منظمة الصحة العالمية، المجلد التاسع، العدد ع، ب..ب 


\section{Malaria parasites}

The type and prevalence of malaria infections (i.e. Plasmodium vivax and $P$. falciparum) recorded in each governorate between 1980 and 2001 were provided by MOHP.

\section{Environmental variables}

Climatic data included the annual mean maxima and minima for temperature, relative humidity and rainfall. These data were collected from The climatic atlas of Egypt [4]. Data on the atlas are based on longterm (25-30 years) climate monitoring.

The geological map of Egypt (Egyptian Geological Survey and Mining Authority, scale $1: 1000000$ ), the soil and terrain units map (provided in digital format by the Soil Sciences Division, National Authority for Remote Sensing and Space Sciences) and the hydrogeological map (Research Institute for Groundwater, Water Research Centre, Ministry of Water Resources and Irrigation, scale 1:1 000000 ) were developed into thematic layers in the GIS.

Socioeconomic data were obtained from The statistical year book [5] and included governorate-level information on total population, average number of households, crowding index (number of persons/ room), sanitary conditions index (total number of houses connected to public sanitary drainage:total number of houses not having such service).

\section{Data integration and analyses}

Tabular epidemiological, environmental and socioeconomic data were linked to respective governorates in the GIS. The base map, geology, soil and hydrogeology layers were geometrically corrected to the same projection. Information collected during our study was used to generate updated maps of the distribution of all anopheline mosquitoes in Egypt as well as the main malaria vectors, An. pharoensis and An. sergentii.

To identify the hydrogeological features of each governorate and to calculate the proportion that each feature occupies within their boundaries, the governorate boundaries and hydrogeological layers were intersected. The data generated, together with those of epidemiological, climatic and socioeconomic variables, were exported to SPSS software (SPSS, Chicago, Illinois) for statistical analysis.

Based on MOHP malaria parasite prevalence records that cover the last two decades, a score for decadal malaria positivity was calculated for each governorate. The first decade covers the period 1982-1991 and the second 1992-2001. For any given year, a governorate was considered malaria-positive if at least one malaria case was officially recorded by MOHP. The score for decadal malaria positivity was calculated as the number of years a governorate was scored positive for malaria during the particular decade, i.e. number of malariapositive years/10. Cluster analysis was then used to sort governorates into 2 distinct categories of malaria risk (high and low) based on the calculated scores of decadal malaria positivity. This type of cluster analysis allows an observation to appear in only one cluster. Governorates were then labelled for analysis purposes according to their malaria risk categories.

A discriminant analysis was performed in SPSS (stepwise procedure) using epidemiological, climatic, socioeconomic and hydrogeological variables to identify the combination of variables that best predicted malaria risk during each of the 2 decades. Additional GIS spatial analysis combining the predictors already identified in the discriminant model with other data sets allowed the identification of the environmental envelope of malaria risk. A map de- 
lineating priority governorates for malaria control and/or surveillance in Egypt was produced based on the analyses of the results.

\section{Results}

\section{Mosquito vector distribution}

Anopheles pharoensis was collected repeatedly from east Port Said to North Sinai governorate in the area of El Salam Canal development project. No anopheline species were collected in Toshka irrigation project, Aswan governorate. Anopheles multicolor was collected near Port Safaga. Anopheles sergentii was absent between Hurghada and Marsa Alam, Red Sea governorate.

The current spatial distribution of An. pharoensis and An. sergentii, the main vectors of malaria in Egypt, as well as their codistribution are shown in Figure 1. Anopheles pharoensis is more widely distributed than An. sergentii, indicating more ecological plasticity. Anopheles sergentii appears to be spreading to new areas and environments, including the suburbs of Cairo. Figure 2 depicts the current diversity and spatial distribution of Anopheles spp. in Egypt. Eleven species are currently extant, with the highest species diversity in North Sinai and South Sinai governorates.

\section{Malaria risk mapping}

The scores of decadal malaria positivity varied greatly in space and time during the study period. Between 1982 and 1991, malaria was reported in 7 governorates, Port Said, Suez, Sharkia, Menofia, Beni Suef, Fayoum and Aswan (Figure 3). Scores ranged between 0.1 and 0.2 for all positive governorates except Fayoum, which was positive for all 10 years (decadal malaria positivity score $=1$ ). Between 1992 and 2001, however, malaria was recorded only in Fayoum, with a score of decadal malaria positivity of 0.6 .

Cluster analysis classified Fayoum as the only high risk governorate during both study decades, while the rest were classified as low risk $(P=0.0001)$. The discriminant model was able to correctly classify $96.3 \%$ of the governorates to their respective risk category. The eigenvalue was 1.085 and the canonical correlation coefficient was 0.916 , indicative of strong discriminant function. The two variables contributing most to risk discrimination were the presence of $P$. falciparum malaria and the hydrogeological unit described as "local and low to moderate productive aquifer, with possible deeper highly productive aquifers." When hydrogeological units were tested alone as predictors, the discriminant model was still able to correctly classify $96.3 \%$ of malaria risk. Wilk's lambda was 0.493 and the canonical correlation coefficient was 0.712 , indicating good discrimination. Results indicated that Fayoum has a significantly higher $(P=$ 0.0001 ) percentage of the identified hydogeological unit (45.3\%) within its boundary compared to the low risk governorates (3.3\%).

Since the discriminant model identified Fayoum as the only high risk area, we used GIS spatial operations to further characterize its environmental envelope. Accordingly, the Anopheles vectors present in the governorate as well as the landform (soil type) characterizing its landscape were identified. Both An. pharoensis and An. sergentii were present in Fayoum, where the landform was identified as "major depression."

To test whether the hydrogeological features and landform characterizing Fayoum occur elsewhere in Egypt, maps delineating the spatial patterns of these features were generated (Figures $4 \mathrm{~A}$ and $4 \mathrm{~B}$ ). Re-

المجلة الصحية لشرق المتوسط، منظمة الصحة العالمية، المجلد التاسع، العدد ؟، ب.. 


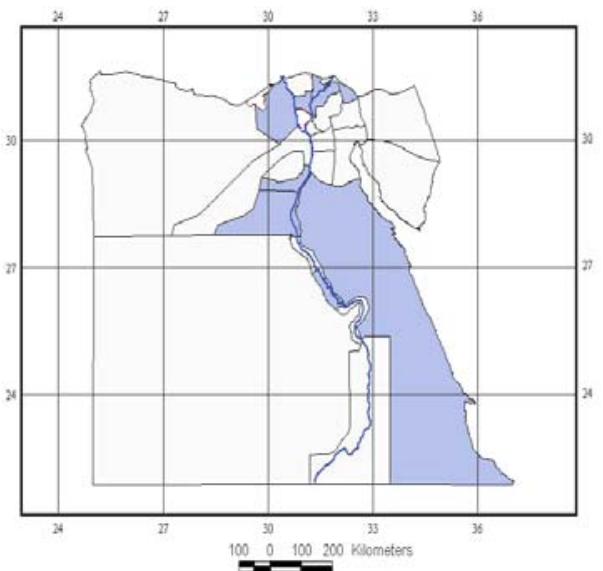

(A)

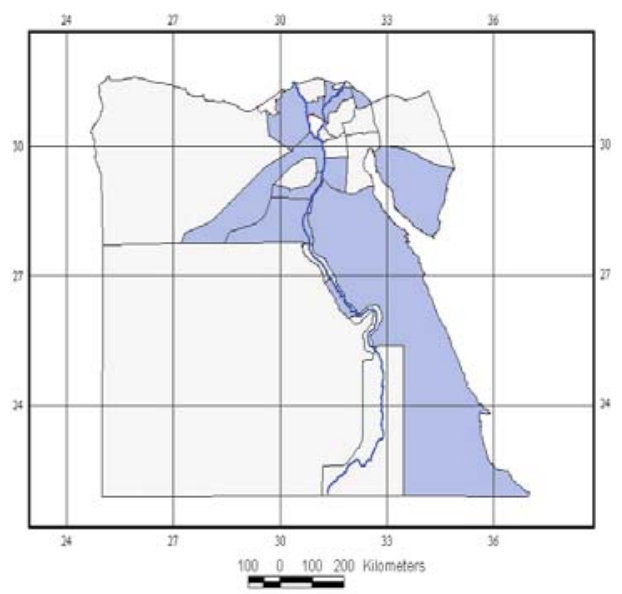

(C)

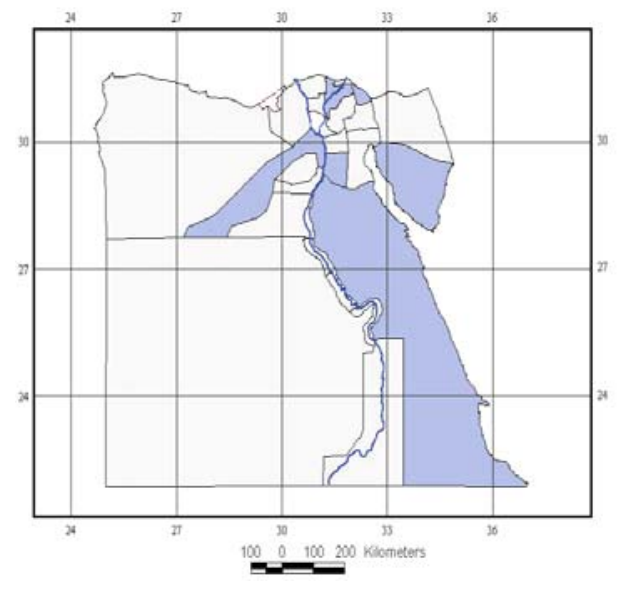

(B)
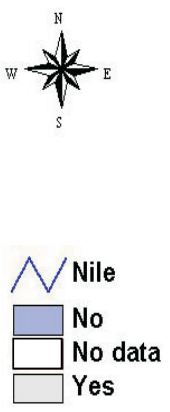

Figure 1 Current geographic distribution of the malaria vectors An. sergentii (A), An. pharoensis (B) and both species in the same governorate (C) in Egypt

sults indicated that these features occur separately in other parts of the country. However, when the two maps were intersected, it became evident that these features spatially coincide only in Fayoum governorate (Figure 4C). It was further indicated by GIS spatial analyses that Fayoum was the only governorate in Egypt where both malaria vectors are present, either alone or in combination with each other, in landscapes characterized by the previously identified hydrogeological and landform features. These results indicate that Fayoum has a unique environmental envelope of biotic and abiotic variables favouring malaria transmission. 

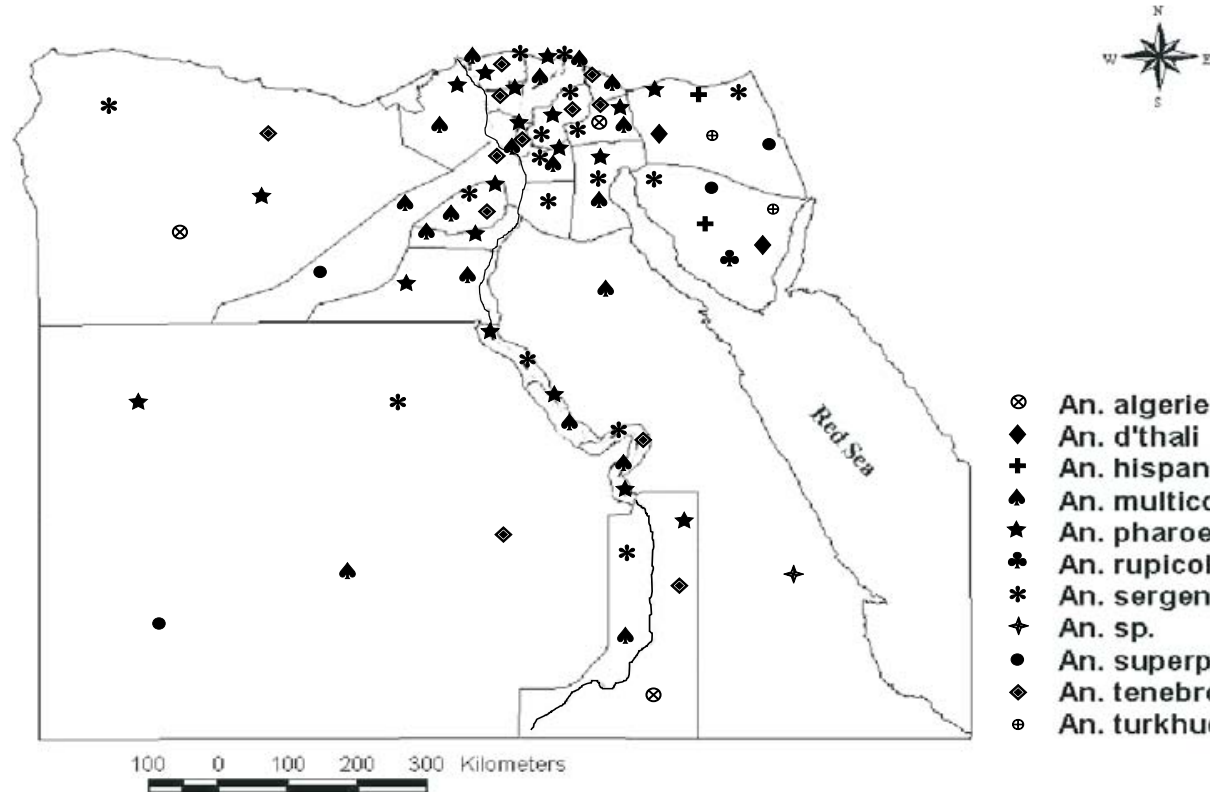

$\otimes$ An. algeriensis

- An. d'thali

+ An. hispaniola

- An. multicolor

* An. pharoensis

* An. rupicolus

* An. sergentil

+ An. sp.

- An. superpictus

- An. tenebrosus

$\oplus$ An. turkhudi

\section{Discussion}

Our data indicated that An. sergentii is spreading fast to agricultural and urban landscapes in the Nile delta and Nile valley, including Cairo. During the 1980s, this species was reported to be limited to Fayoum, Sinai and oases of the western desert [6]. Anopheles sergentii was then reported in Upper Egypt, in Aswan [7] and in Qena [8] during the 1990s and early 2000s. This trend is epidemiologically important as it expands the risk for malaria transmission by this efficient vector [1]. Thus, as the risk is amplified in governorates where both vectors are present [1], maps of the co-distribution of these two main malaria vectors developed during this investigation may direct attention to governorates with higher priority for surveillance/control.
Quantitative data on vector abundance are, however, urgently needed to strengthen risk assessment and to assist in the development of malaria predictive models.

The geographic distribution of An. sergentii is dynamic and appears to be influenced by ecological changes and subsequent adaptation. This species was not found in the Red Sea governorate, where it had been reported previously $[2,9]$. This may be due to the decrease in water availability that led to a huge change in the ecology of the habitat. In this habitat An. sergentii was replaced by Culex deserticola.

The occurrence of An. multicolor near Port Safaga in the Red Sea governorate indicates a further and recent extension of this species northwards along the Red Sea coast.

المجلة الصحية لشرق المتوسط، منظمة الصحة العالمية، المجلد التاسع، العدد ع، ب... 


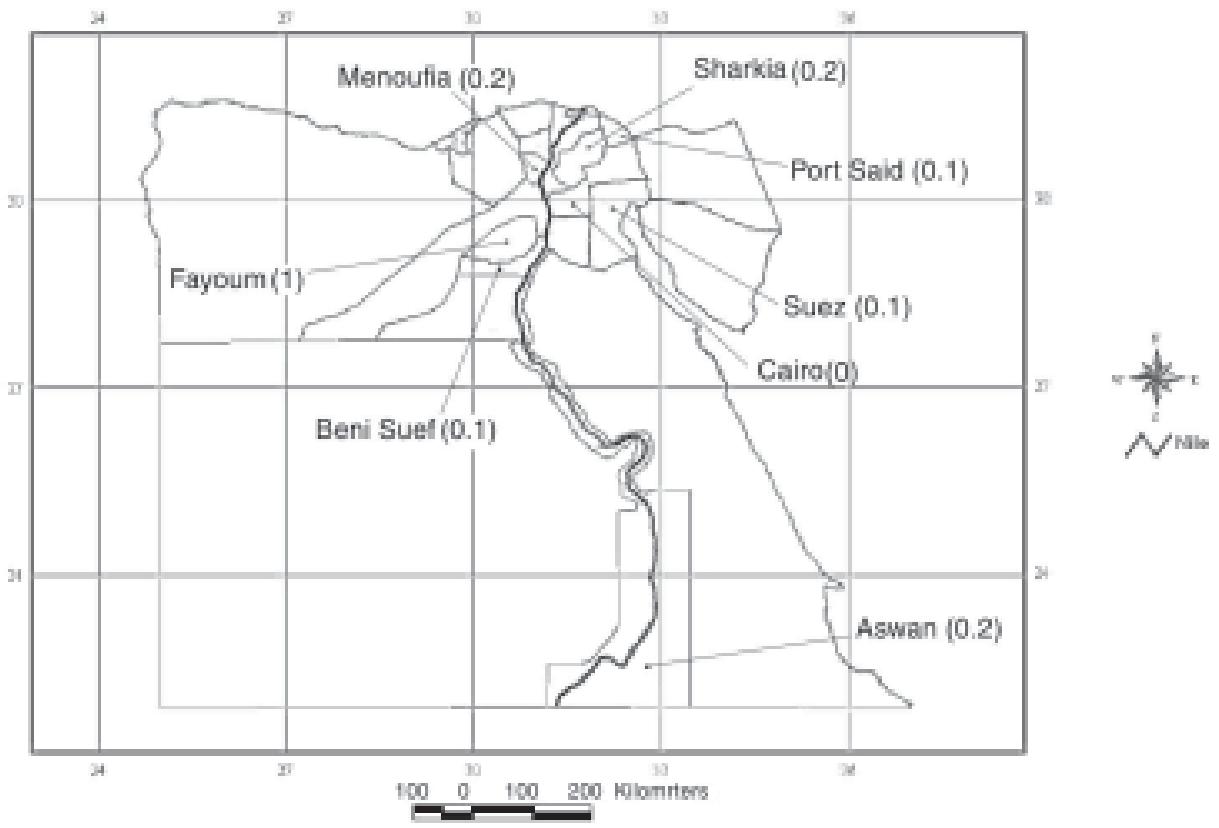

Figure 3 Map of Egypt showing malaria positivity scores (0-1.0) at governorate level, 1982-1991

The presence of An. pharoensis in the area of El Salam Canal water resources development project draws attention to a potential malaria risk if carriers are introduced through the workforce. The results indicate that the distribution of Anopheles vectors is dynamic, thus requiring continuous monitoring and updating to provide an indicator of malaria entomological risk.

According to the concepts of landscape epidemiology and the doctrine of nidality, diseases have natural habitats in the same way as species: they are found in focal areas where the spatial distribution of the parasite, host, vector and required environmental conditions coincide [10]. Our findings indicate that malaria risk can be predicted based on physical features only, i.e. hydrogeology and soil. This was strongly linked to vector distribution in ar- eas characterized by unique physical features, e.g. Fayoum. By using both GIS and statistical analysis we were able to identify the unique physical features of this governorate that contribute to its high risk situation.

Fayoum is characterized by being lower than sea level and by gradual decrease in elevation [11]. Elevation tends to decrease gradually from $+26 \mathrm{~m}$ to $-45 \mathrm{~m}$ at the southern tip of Lake Qarun. These physical features, together with excessive use of irrigation water and inefficient agricultural drainage, have created several problems, including a marked increase in the watertable, formation of swamps and ponds and soil salinization [11], leading to the shaping of ecological conditions conducive to mosquito breeding and consequently to higher risk of malaria transmission. 


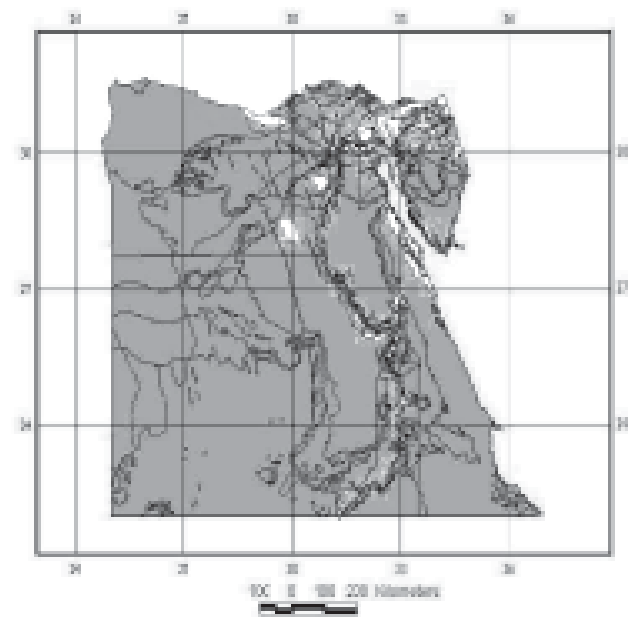

(A)

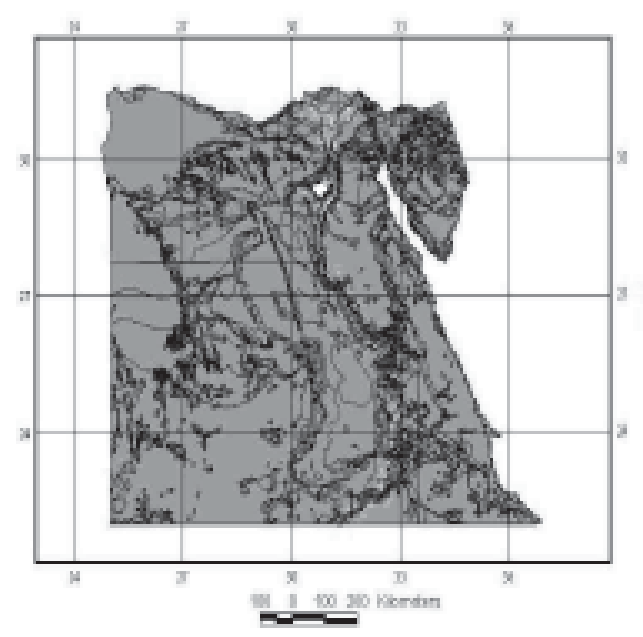

(C)

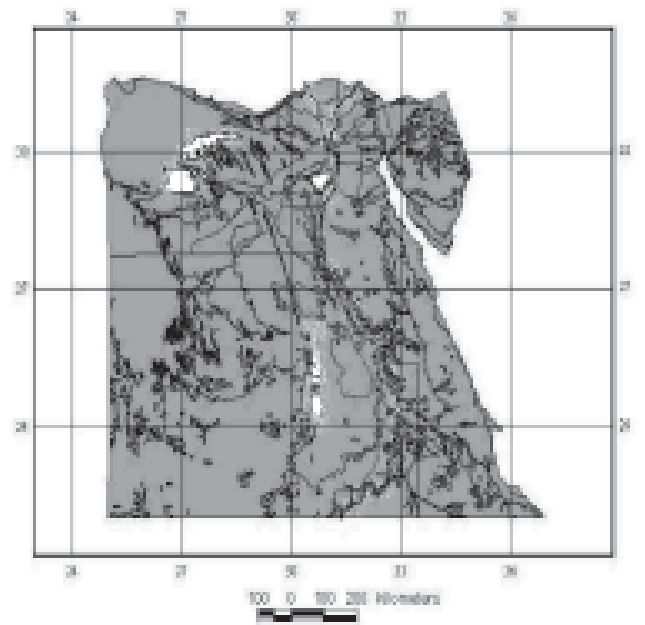

(B)
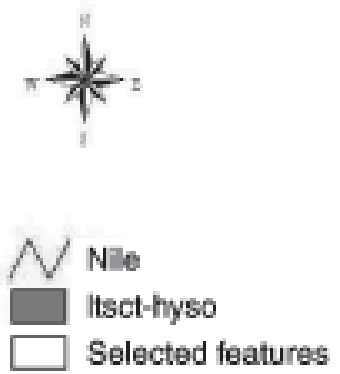

Figure 4 Spatial patterns of hydrogeological units (A) and soil types (B) characterizing areas of high risk for malaria transmission and areas of Egypt where these features coincide (C) (selected features are shown in white)

Managing malaria in Fayoum would require more than the conventional control methods as the physical features of this area must be taken into consideration. The large waterlogged and swampy areas where thick emergent vegetation cover exists make access, and hence conventional mosquito control methods, very difficult (MOHP, unpublished data, 2001). Therefore, environmental management tech-

المجلة الصحية لشرق المتوسط، منظمة الصحة العالمية، المجلد التاسع، العدد ع، ب... 
niques, including water-table/surface water management, should be adopted in integration with conventional methods of vector control. These management techniques may include planting of trees with high evapotranspiration potential to lower the water-table, water-lowering engineering methods, mass vegetation clearance, etc. This would, of course, require intersectoral cooperation and coordination at the local level.

Our results support findings of previous research that environmental factors are important determinants of vector-borne disease risk [12]. Malaria is known to be associated with high water-table and soil type [13] as well as to elevation and terrain [14] in other parts of the world. Similar analyses combining environmental/landscape variables and epidemiological data have been used to predict the risk of malaria transmission $[15,16]$.

Although only Fayoum governorate was identified as a high risk area for malaria, other areas in Egypt may be vulnerable, particularly Aswan and Cairo governorates. The 2 main malaria vectors in Egypt, $A n$. pharoensis and An. sergentii, are established in both governorates. Aswan is located near the southern border of Egypt, where a continuous influx of potential malaria carriers enters routinely and where new transportation routes are being developed. In addition, the huge desert barrier between Aswan and Sudan is the target of a major water and agricultural development activity, the Toshka project. No Anopheles species have been found there yet, but with the expected ecological succession, malaria vectors could become established.

Cairo is home for a huge number of Asian and African people who reside there for educational and religious purposes. Thus, a risk exists deriving from the potential presence of infected people coincident with an efficient vector. Detailed mapping of the locations of settlements of potential human sources and mosquito breeding sites is essential to establish a hazard assessment programme in Cairo. A map of malaria high risk and vulnerable governorates was generated to assist in prioritization of surveillance and preparedness activities in Egypt (Figure 5).

This study sets the stage for the development of a more comprehensive database on malaria in Egypt. Although it is crucial to have a database at the governorate level, smaller administrative levels should also be considered to account for variations on smaller scales. Our findings also provide the basic framework for developing an early warning system for malaria in Egypt through monitoring of vector distribution and mapping these data in relation to environmental variables such as hydrogeology and soil. Moreover, the successful cooperation experienced throughout this investigation between health authorities and research institutions should be repeated to include other important diseases and should be expanded to include Regional cooperation in the fight against vector-borne diseases of Regional interest.

\section{Acknowledgements}

This investigation received technical and financial support from the joint WHO Eastern Mediterranean Region (EMRO), Division of Communicable Diseases (DCD) and the WHO Special Programme for Research and Training in Tropical Diseases (TDR): the EMRO/DCD/TDR Small Grants Scheme for Operational Research in Tropical and Communicable Diseases.

The authors would like to thank A. Khatab, H. El Hussieny and M. Ghadiry whose assistance was highly appreciated. 


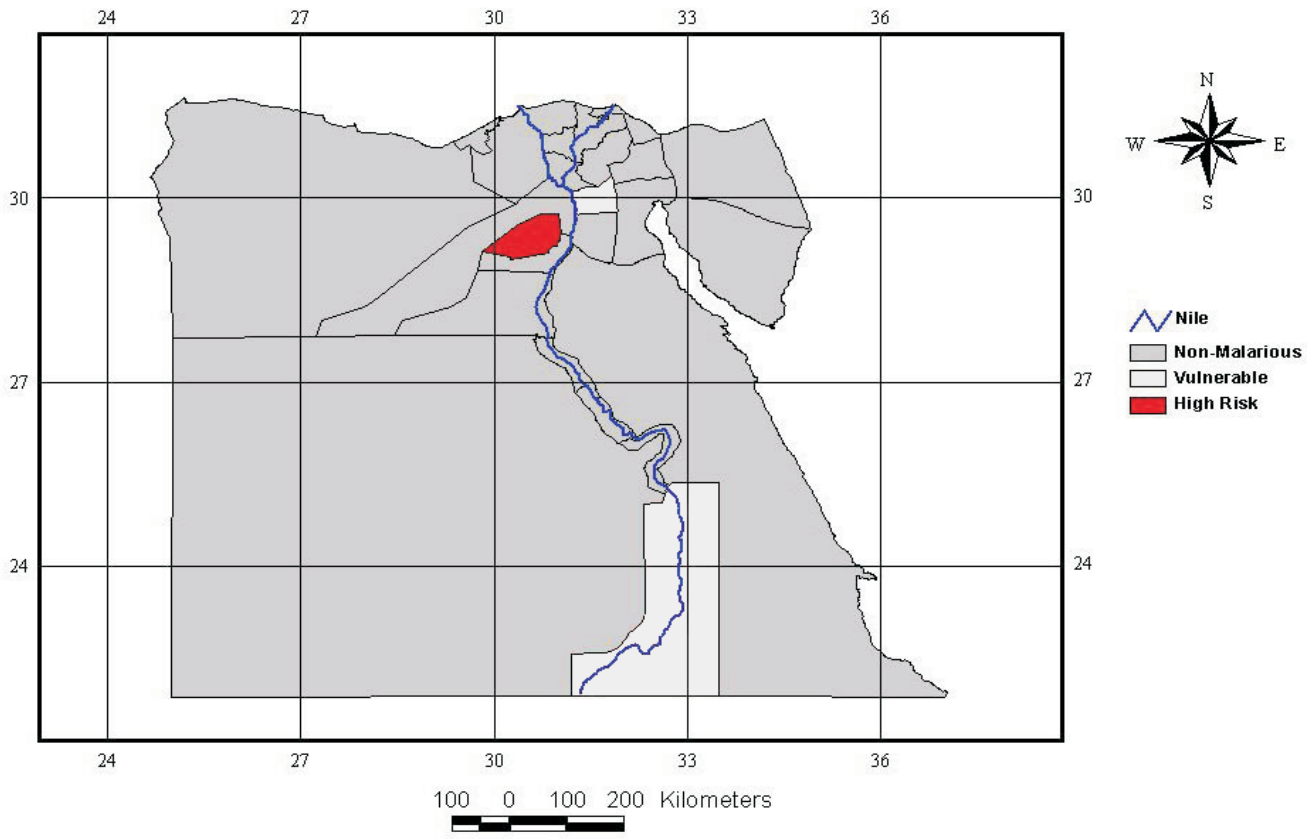

Figure 5 Malaria surveillance/control priorities in Egypt based on risk and vulnerability to transmission

\section{References}

1. Kenawy MA. Anopheline mosquitoes (Diptera: Culicidae) as malaria carriers in A.R. Egypt "History and present status." Journal of the Egyptian Public Health Association, 1988, 63(1+2):6785.

2. Harbach RE et al. Records and notes on mosquitoes (Diptera: Culicidae) collected in Egypt. Mosquito systematics, 1988, 20 (3):312-41.

3. Birley $\mathrm{MH}$. Guidelines for forecasting the vector-borne disease implications of water resource development. Geneva, World Health Organization, 1989 (VBC/ 89.6).

4. The climatic atlas of Egypt. Cairo, Egyptian Meteorological Authority, 1996.
5. The statistical year book. Cairo, Central Agency for Public Mobilization and Statistics, 2001.

6. Kenawy MA. Fauna of anopheline mosquitoes (Diptera:Culicidae) in A.R. Egypt. "Historical background and present situation." Journal of the Egyptian Public Health Association, 1990, 65 $(3+4): 263-81$.

7. Cope SE, Gad AM, Presley SM. New record of the malaria vector Anopheles sergentii in the Southern Nile Valley of Egypt. Journal of the American Mosquito Control Association, 1995, 11(1):145-6.

8. Mostafa AA, Allam KA, Osman MZ. Mosquito species and their densities in some Egyptian governorates. Journal of the

المجلة الصحية لشرق المتوسط، منظمة الصحة العالمية، المجلد التاسع، العدد ع، ب... 
Egyptian Society of Parasitology, 2002, 32(1):9-20.

9. Gad AM et al. The distribution and ecology of mosquitoes in the Red Sea Governorate, Egypt. Journal of the Egyptian Society of Parasitology, 1987, 17(1): 207-21.

10. Pavlovsky EN. The natural nidality of transmissible disease. Urbana, University of Illinois Press, 1966.

11. National project for the development of the northern Nile Valley (1995-2017). Cairo, Ministry of Planning, 1996.

12. Bergquist NR. Vector-borne parasitic diseases: new trends in data collection and risk assessment. Acta tropica, 2001, 79(1):13-20.

13. Srivastava A et al. Geographic information system as a tool to study malaria receptivity in Nadiad Taluka, Kheda dis- trict, Gujarat, India. Southeast Asian journal of tropical medicine and public health, 1999, 30(4):650-6.

14. Nalim S et al. Rapid assessment of correlations between remotely sensed data and malaria prevalence in the Menoreh hills area of central Java, Indonesia. Geneva, World Health Organization, 2002 (WHO/SDE/WSH/02.06).

15. Beck LR et al. Remote sensing as a landscape epidemiologic tool to identify villages at high risk for malaria transmission. American journal of tropical medicine and hygiene, 1994, 51(3): 271-80.

16. Sharma VP, Srivastava A. Role of geographic information system in malaria control. Indian journal of medical research, 1997, 106:198-204. 